\title{
Relational communication, emotional intelligence, and marital satisfaction
}

\author{
Masood, Afsheen $\>$ \\ Institute of Applied Psychology, University of the Punjab, Lahore, Pakistan (Afshen1402@gmail.com) \\ Mazahir, Shama \\ Institute of Applied Psychology, University of the Punjab, Lahore, Pakistan (Shamamazahir8885@gmail.com)
}

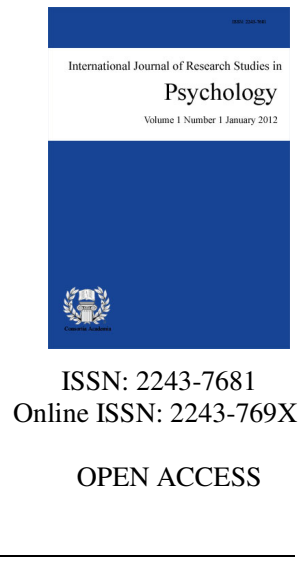

Received: 26 March 2015

Revised: 5 June 2015 DOI: $10.5861 / \mathrm{ijrsp} .2015 .1159$

Accepted: 10 June 2015

OI: $10.5861 / 1 \mathrm{jrsp} .2015 .1159+2.000$

\begin{abstract}
This research was designed to investigate the role of relational communication and emotional intelligence on quality of marital satisfaction. This is hypothesized that effective communication and higher emotional intelligence is likely to predict the greater marital satisfaction. The sample for the current research comprised of 100 married couples taken from diverse family setups, i.e. nuclear vs. Joint. The age range of the participants was from 20 years to 55 years of age. Translated, adapted and validated Emotional versions of Intelligence Scale (Schutte et al., 1998), Marital Satisfaction Inventory Revised (Snyder, 1997) and Relational Communication Scale (Burgoon \& Hale, 1987) were employed for data collection. Pearson product moment correlation was employed to find relationship between relational communication, emotional intelligence and marital satisfaction. The results indicated that there is significant relationship between relational communication, emotional intelligence and marital satisfaction. Regression analyses revealed that emotional intelligence, husband's education, monthly income and family system emerged as strong predictors of marital satisfaction. The findings carry strong implications for the family therapists, marital counselors and researchers in the domain of family studies.
\end{abstract}

Keywords: marital satisfaction; emotional intelligence; relational communication; interpersonal relationship; marital therapy/counseling 


\section{Relational communication, emotional intelligence, and marital satisfaction}

\section{Introduction}

Marriage is a major pillar of a society because it offers the initial structures to establish family relation and to train future generation. Communication is important in determining the health of marital relations. A number of factors affect the marital communication like emotional intelligence, emotional alertness, emotional appearance, emotional maintenance and compassion. This exploration aimed to investigate the relation among the relational communication, emotional intelligence and marital satisfaction.

\subsection{Relational Communication}

Relational Communication refers to those ways in connection-making that people generally used to deal with their relation issues. There are various ways to communicate with each other but most of the literature heighted three major styles that includes mutual constructive pattern, one's demanding and other withdrawing behavior and mutual avoidance approach. First patterns suggest expressing of feeling and positive approach of other partners to resolve issues. In second case, one partner will tries to talk about issues by condemning, complaining, or proposing solutions while other partner tries to avoid the talk by simply escaping from situation or by denying problem. While in case of mutual avoidance, both partners avoid discussion on the problem (Hezardastan et al., 2011).

Abundant researches have demonstrated that the quality of a couple's communication is associated with their marital satisfaction. A study was conducted on the relation between communication styles and marital satisfaction in those of the students of universities of Tehran, indicated when both partners had adopted positive approach towards their issues then they reflected greatest martial satisfaction while it deceased with use of other two approaches (Amiri et al., 2011). Results of another study suggested a direct relation in dissatisfaction and demander draw communication approach and inverse relation in dissatisfaction and constructive interaction style (Madahi et al., 2013). Similarly, Raeisipoor, Fallahchai, and Zarei (2013) conducted a research on attachment patterns in adults, ways of communication, and marital satisfaction, which proposed a multiple associations among these to variables. These researches are clearly reflecting the central role of communication in marriage.

\subsection{Emotional Intelligence}

Generally emotional intelligence is defined as an individual sensitivity towards emotions. Boyatzis and Sala (2004) define it as a group of attributes or characteristics to identify and utilized specific knowledge regarding self and other emotions to mastery a situation in effective manner. Literature suggested three model of emotional intelligence. First model is called ability model given by Peter, John and David (2004) it proposed about the individual ability of analysis social situations through his/her knowledge regarding emotions. Konstantin, Furnham, and Adrian (2001) suggested second trait model includes behavioral characters and capacities in refer to self-perception that is assessed by self-report. Final model is mixed one given by Daniel Goleman (1998), which is a combination of first two models. It is describes as a set of abilities and competences that elicit appropriate situation specific response. Daniel Goleman gave four components of the EI i.e. Self-consciousness, self-organization, social alertness and relationship management. Relationship management means the ability to use awareness of personal emotions and those of other to manage the communication patterns.

Dehkordi (2012) investigated about couples' emotional intelligence and marital satisfaction, which proposed that both partner's emotional intelligence and marital satisfaction had direct relation. Batool and Khalid (2009) examined the effect of emotional intelligence on martial relations and evidenced that there was great importance of EI in spousal relationship. Another research conducted on academic members of Rafsanjon University 
Relational communication, emotional intelligence, and marital satisfaction

indicated a strong association in between emotional intelligence and marital satisfaction (Hasani et al, 2012).

\subsection{Marital Satisfaction}

Marital satisfaction means adoption matrimony as change in personal life and expectation that leads to new experiences. Socialists believed that it is one's adjustment to the current circumstance and his/her expectations or ideal situations. Theorist believed that marriage is an important part of nature cycle of extending human race. Hagins explained marital satisfaction as feeling contentment, joy and fulfillment by couple in all the phase of marital life. Hence it could say that marital satisfaction is an individualized feeling of approval, contentment and pleasure in one towards his/her partner (Smith et al., 2008).

Results of study carried out on communication patterns, emotional intelligence and marital satisfaction reflected that an individual perception of their personality and the couple communication patterns were the strongest predictor of their satisfaction (Smith et al., 2008). Similarly, outcomes of another study conducted on the association of emotional intelligence and life satisfaction determined a reliable link in emotional intelligence and satisfaction, which can be substantially enhanced by providing communication skill training (Ghorbanshiroudi et al., 2011). According to another research investigated the mediating effect of intimacy on association of emotional skillfulness and marital satisfaction highlighted that marital adjustment of couples depend on their ability to interpret and communicate each other emotions (Cordova et al., 2005).

The perspective from eastern family structures especially from Pakistan is empirically being missing. With newer trends introduced in Pakistani realm related to family disruptions and divorce have added impetus for the current research. There is dire need to identify all risk and protective factors that could improve the spousal relations and therefore could prove to be the buffers for family break ups. The phenomenon of marital satisfaction has been systematically been studied through this research and scanty researches representing Pakistani society based data and exploring how these western well-researched topic disseminates its impact is fruitful contribution here. Hence it could be concluded that emotional intelligence improvement can be used as intervention during couple therapy. To achieve this task it is better to first target their behavioral issues and communication skills.

\subsection{Rational}

Emotional intelligence is one's characteristics that helps individual to communicate well with other through verbal and nonverbal signs. In case of marital relational, these two variables plays important role in determining couple satisfaction towards each other.

\subsection{Hypotheses}

$>$ There is likely to be a relation among relational communication, emotional intelligence and martial satisfaction of couples.

$>$ Demographics (age, education, family set up, family income and marriage duration), Relational Communication and emotional intelligence are likely to predict the marital satisfaction of couples.

$>\quad$ There is likely to have gender difference in relational communication, emotional intelligence and martial satisfaction of couples.

$>\quad$ There is likely to be difference in martial satisfaction of couple having different education levels.

$>\quad$ There is likely to be difference in relational communication of couple having different education levels.

$>\quad$ There is likely to be difference in martial satisfaction of couple having different family incomes. 


\section{Method}

\subsection{Research design}

This research was laid through cross sectional research design. Nonprobability purposive sampling was adopted to select the potential participants of the research.

\subsection{Sample}

The sample consisted of 50 couples among them, mean age of husband is 46 and mean age of wives is 36 . The majority of the participants were from urban region and lived in joint set ups. The participants were categorized into three groups i.e., under graduates, graduates and post graduates. This sample included 22 couples with income between 5-15 thousands, 25 couple with income between 16 to 25 thousands, while 40 couples with income more than 26 thousand. The demographics of the sample have been reviewed below:

Table 1

Demographics of the sample $(n=100)$

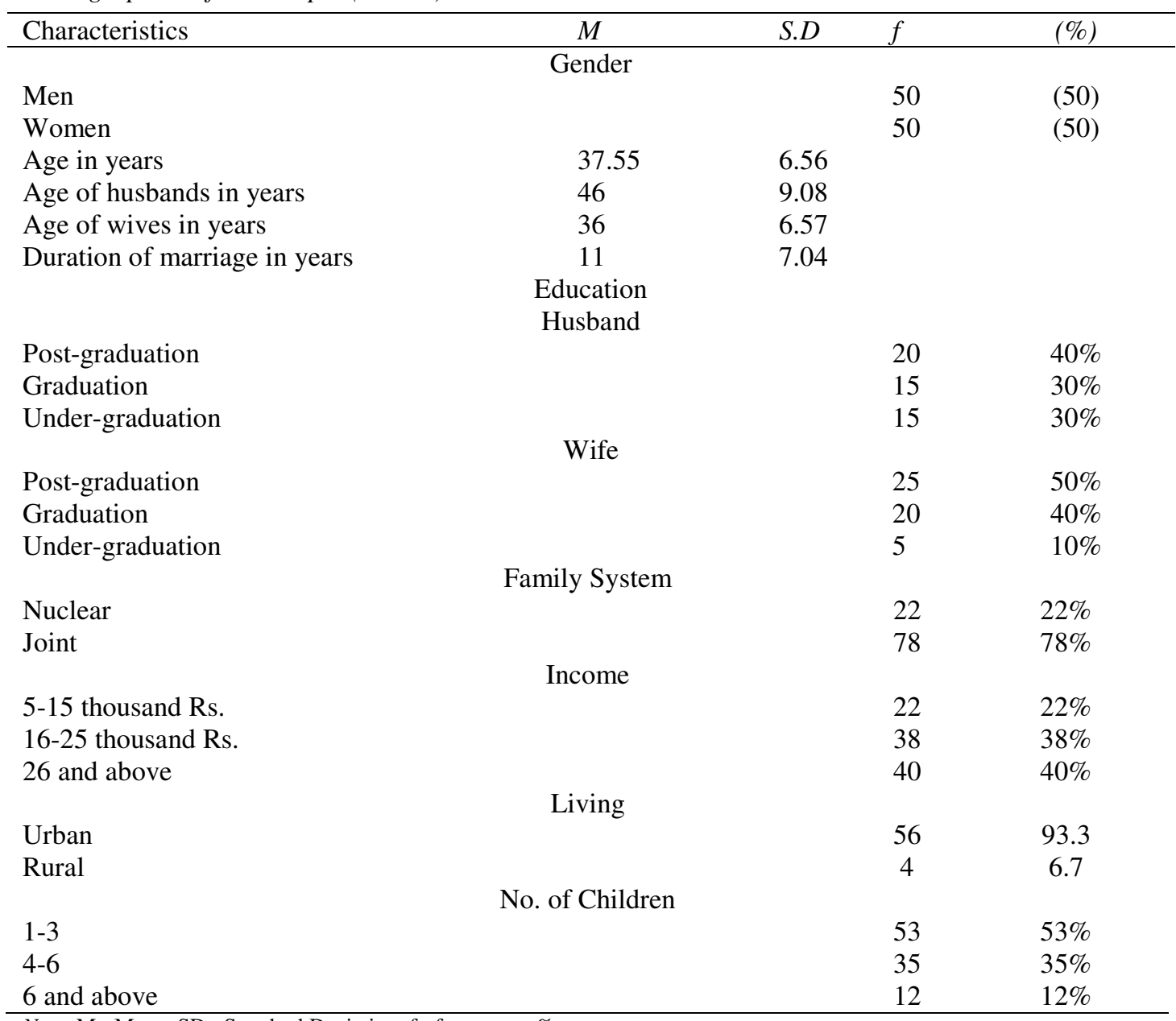

Note. $\mathrm{M}=$ Mean; $\mathrm{SD}=$ Standard Deviation; $\mathrm{f}=$ frequency; \%= percentage

\subsection{Measures}

This is difficult to measure the broad constructs of emotional intelligence and marital satisfaction with their depth and expansion but as attempt has been made herewith to include all relevant dimensions of these two constructs that pertain to the domain of marital satisfaction. 
Emotional Intelligence Scale (Schutte et al., 1998) - This scale consists of 33 items which were rated on five point likert scale, which are developed on the basis of Salovey and Mayer model of EI in 1990. Scoring is done by reversing the score of some of the item and then calculating the sum of all the items. Score is varied from 33 to 165 , sharper aspects of emotional intelligence, as the score get high. The scale was translated in to Urdu language. The reliability coefficient of the scale for the current data is alpha 0.89 .

Relational Communication Scale (Burgoon \& Hale, 1984) - It described relation communication as interpersonal communication based on the combination of the various themes of the verbal and nonverbal communication ways of people. They gave 12 aspects of relational communication on the basis of their analysis of the literature. These dimensions are Dominance-Submission, Intimacy, Affection-Hostility, Intensity of Involvement, Inclusion-Exclusion, Trust, Depth-Superficiality, Emotional Arousal, Composure, Similarity, Formality, and Task-Social Orientation. They developed RCS in 1987 which contained 64 items that rated on 5 point likert scale. For the eight dimensions reported values for coefficient alphas range from .42 to .88 .

Marital Satisfaction Inventory Revised (Snyder, 1997) - This instrument comprised of 150 dichotomous items which measure nature and intensity of the relationship strength in 13 different domains. These domains includes conventionalization, global agony, affective communication, problem solving communication, aggression, time together, disparity about finances, sexual dissatisfaction, role orientation, family past of distress and fight regarding child nurturing, last domain assesses consistency in individual responses. The internal consistency value of all these sub scales vary from alpha .70 to .93 , with an average value of .82 . This inventory was translated in Urdu language and reliability value of translated version of this inventory for this data is alpha .76 .

Self-constructed demographic Questionnaire - Information related to age, education, family system, family income, residence, marriage duration and no. of children were included in an indigenous self-constructed form.

\subsection{Procedure}

This research was executed after seeking permission and approval of all involved ethics and review committees. The study consisted of two parts. In the first part of the study, Emotional Intelligence Scale (Schutte et al., 1998) and Marital Satisfaction Inventory Revised (Snyder, 1997) were adapted and validated. The items of the scales were presented to bilingual educators in order to translate each item in such a way that the conceptual meaning contained in each item was adequately conveyed through the items in Urdu. The translated scales were then examined for accuracy of conceptual meaning. Those items which had similar conceptual meanings to that of items in original scales were kept in translated scales. Then cultural relevance of each item was also assessed. The translated scales were then given to 10 participants who confirmed that each item was relevant to Pakistani culture and was thus considered as the final format of the scale.

The translated versions of 33-items Emotional intelligence scale and 150- items Marital Satisfaction Inventory Revised were used for the purpose of the present study. The reliability and validity of the scales were also determined by administering the scales to participants. For translated scales reliability co-efficient was found .91 and .76 respectively whereas the original scales have reliability coefficient 0.90 and 0.82 respectively. In the second part of the study, data was collected from partners separately. For the purpose of data collection, all ethical considerations were kept in mind. After giving adequate instructions, demographic sheet and questionnaires were administered. Confidentiality of the information taken from the participants was ensured. The average time taken for data collection was 25 minutes from one participant. Then data was analyzed and discussion and conclusion were made. 
Masood, A., \& Mazahir, S.

\section{Results}

Data was analyzed by using SPSS version 16.0.

\section{Table 2}

Pearson Product Moment Correlation of Study Variables $(N=100)$

\begin{tabular}{lcccccccc}
\hline & 1 & 2 & 3 & 4 & 5 & 6 & $M$ & $S D$ \\
\hline 1. Emotional Intelligence & -- & $.63^{*}$ & $.68^{* *}$ & $.61^{*}$ & .43 & -- & 101 & 13.08 \\
2. Relational Communication & -- & -- & $.58^{*}$ & $.54^{*}$ & $.61^{* *}$ & $.58^{*}$ & 98 & 7.39 \\
3. Marital Satisfaction & -- & -- & -- & $.43^{*}$ & .38 & .41 & 94 & 10.18 \\
4. Education & -- & -- & -- & -- & .32 & $-.35^{*}$ & 14 & 3.25 \\
5. Marital Duration & -- & -- & -- & -- & -- & .31 & 19 & 6.53 \\
6. No. of Children & -- & -- & -- & -- & -- & -- & 7 & 0.18 \\
\hline Note. Only significant correlations reported from demographics. & ${ }^{*} p<.05 ;{ }^{* *} p<.01$ & & & &
\end{tabular}

Result demonstrates a strong relation among emotional intelligence, rational communication, marital satisfaction and education level of the partners. It also highlighted the strong positive relation in marriage duration with relational communication and marital satisfaction.

\section{Table 3}

Hierarchical Regression Analysis for Marital Satisfaction $(N=100)$

\begin{tabular}{lcc}
\hline \multicolumn{1}{c}{ Step and Predictor Variables } & $\Delta \mathrm{R}^{2}$ & $\beta$ \\
\hline Step 1 & $0.45^{*}$ & $0.04^{*}$ \\
Emotional Intelligence & & $0.35^{*}$ \\
Step 2 & & $0.73^{*}$ \\
Husband's Education & $0.03^{*}$ & -0.01 \\
Husband's Occupation & & 0.04 \\
Step 3 & & 0.31 \\
Age & $0.03^{*}$ & $-0.13^{* *}$ \\
Education & & $-0.16^{* *}$ \\
Monthly Income & & $-.33^{*}$ \\
Step 4 & &
\end{tabular}

Results highlight that emotional intelligence predicts $35 \%$ while husband's education determines $57 \%$ whereas monthly income directs $62 \%$ on the other hand family income and marriage exhibits $68 \%$ of the marital satisfaction.

\section{Table 4}

T-test for gender difference in Emotional Intelligence, Martial Satisfaction, \& Relational Communication $(N=100)$

\begin{tabular}{|c|c|c|c|c|c|c|c|c|c|}
\hline \multirow[t]{2}{*}{ Variables } & \multicolumn{2}{|c|}{$\begin{array}{l}\text { Male } \\
(\mathrm{n}=50)\end{array}$} & \multicolumn{2}{|c|}{$\begin{array}{l}\text { Female } \\
(\mathrm{n}=50)\end{array}$} & \multirow[b]{2}{*}{$t(98)$} & \multirow[b]{2}{*}{$p$} & \multicolumn{2}{|c|}{$95 \% \mathrm{CI}$} & \multirow{2}{*}{$\begin{array}{c}\text { Cohen's } \\
D\end{array}$} \\
\hline & $M$ & $S D$ & $M$ & $S D$ & & & $L L$ & $U L$ & \\
\hline EI & 97 & 13.21 & 92 & 9.31 & 3.43 & $.00^{*}$ & -1.27 & 7.66 & 0.44 \\
\hline MS & 93 & 8.21 & 94 & 5.06 & 4.43 & $.00^{*}$ & -4.34 & 5.67 & -0.15 \\
\hline $\mathrm{RC}$ & 95 & 6.01 & 87 & 5.13 & 3.41 & $.00^{*}$ & 1.21 & 7.56 & 1.44 \\
\hline
\end{tabular}

Note. ${ }^{*} p<.05 ; \mathrm{EI}=$ Emotional Intelligence; $\mathrm{MS}=$ Marital Satisfaction; $\mathrm{RC}=$ Relation Communication; M= Mean; $\mathrm{SD}=\mathrm{Standard}$ Deviation; LL=Lower Limit; UL= Upper Limit; $\mathrm{M}=\mathrm{Mean} ; \mathrm{SD}=$ Standard Deviation

Descriptive indicated that partners indicated difference in using different patterns of relational communication and emotional intelligence but their marital satisfaction is almost equal. 
Relational communication, emotional intelligence, and marital satisfaction

Table 5

One-way ANOVA for Marital Satisfaction with reference to education level of Husband and Wife $(N=100)$

\begin{tabular}{|c|c|c|c|c|c|c|c|c|c|c|c|c|}
\hline \multirow[t]{2}{*}{ Measures } & \multicolumn{3}{|c|}{ Under graduation } & \multicolumn{3}{|c|}{ Graduation } & \multicolumn{3}{|c|}{ Post-graduation } & \multirow[t]{2}{*}{$\mathrm{F}$} & \multirow[t]{2}{*}{$p$} & \multirow[t]{2}{*}{ post hoc } \\
\hline & $\mathrm{n}$ & $\mathrm{M}$ & SD & $\mathrm{n}$ & $\mathrm{M}$ & SD & $\mathrm{n}$ & $\mathrm{M}$ & SD & & & \\
\hline $\begin{array}{l}\text { Marital } \\
\text { Satisfaction }\end{array}$ & 32 & 83 & 7.63 & 36 & 85 & 8.01 & 32 & 97 & 9.46 & 17.38 & 0.00 & $3>1>2^{*}$ \\
\hline
\end{tabular}

Note. ${ }^{*}$ Categories of Education i.e., 1= undergraduation, 2= graduation, $3=$ post graduation; M= Mean; SD= Standard Deviation

Results indicated that post graduated spouses reflect highest marital satisfaction than under graduated couples indicate their satisfaction, but graduated partners show lowest contentment towards their marriage.

Table 6

One-way ANOVA for Relational Communication with reference to education level of Husband \& Wife $(N=100)$

\begin{tabular}{|c|c|c|c|c|c|c|c|c|c|c|c|c|}
\hline \multirow[t]{2}{*}{ Measures } & \multicolumn{3}{|c|}{ Under graduation } & \multicolumn{3}{|c|}{ Graduation } & \multicolumn{3}{|c|}{ Post-graduation } & \multirow[t]{2}{*}{$\mathrm{F}$} & \multirow[t]{2}{*}{$p$} & \multirow[t]{2}{*}{ post hoc } \\
\hline & $\mathrm{n}$ & $\mathrm{M}$ & SD & $\mathrm{n}$ & $\mathrm{M}$ & SD & $\mathrm{n}$ & $\mathrm{M}$ & SD & & & \\
\hline $\begin{array}{l}\text { Relational } \\
\text { Communication }\end{array}$ & 32 & 66 & 3.24 & 36 & 55 & 5.33 & 32 & 76 & 5.16 & 16.27 & 0.00 & $3>1>2^{*}$ \\
\hline
\end{tabular}

Results specified that post graduated spouses communicated in most appropriate way than under graduated couples indicate better communication, but graduated partners lack communication skills.

Table 7

One-way ANOVA for marital satisfaction with reference to income level of Husband and Wife $(N=100)$

\begin{tabular}{|c|c|c|c|c|c|c|c|c|c|c|c|}
\hline \multirow[t]{2}{*}{ Measures } & \multicolumn{3}{|c|}{ 5-15 thousand Rs } & \multicolumn{3}{|c|}{$16-25$ thousand Rs } & \multirow{2}{*}{\multicolumn{3}{|c|}{$\begin{array}{l}26 \text { thousand and } \mathrm{F} \\
\text { above } \\
\begin{array}{llll}\mathrm{n} \quad \mathrm{M} & \mathrm{SD}\end{array}\end{array}$}} & \multirow[t]{2}{*}{$p$} & \multirow[t]{2}{*}{ post hoc } \\
\hline & $\mathrm{n}$ & $\mathrm{M}$ & SD & $\mathrm{n}$ & M & SD & & & & & \\
\hline $\begin{array}{l}\text { Marital } \\
\text { Satisfaction }\end{array}$ & 22 & 18 & 2.33 & 38 & 32 & 2.54 & 40 & 4.23 & 13.33 & 0.00 & $3>1>2 *$ \\
\hline
\end{tabular}

Note. ${ }^{*}$ Categories of Education i.e., $1=5-15$ thousands Rs., $2=16-25$ thousands Rs., $3=26$ thousands and above; M= Mean; SD= Standard Deviation

Results indicated that spouses that earned above Rs. 26 thousands reflect highest marital satisfaction, than those made between 5 to 15 thousands indicate their satisfaction, but those received between 16 to 25 thousands show lowest contentment towards their marriage.

\section{Discussion}

The results of this research indicated that there is significantly strong positive relation among emotional intelligence, relational communication and marital satisfaction of married couples. These results are consistent with the previous researches as Smith et al, 2008 conducted a study using these variables and highlighted similar results. Ghorbanshiroudi et al. (2011) also emphasized that communication skill trainings enhanced the individuals' emotional intelligence and becomes a source of improvement in couples' satisfaction towards each other. Thus in orders to safeguard the sanctity of family structure, we as health professionals need to highlight the importance of communication in promoting the healthy family life. Findings also highlighted that emotional intelligence, family system and marriage duration is a predictor of the marital satisfaction. These results are congruent with past studies as Batool and Kalid (2012) that revealed that emotional intelligence acts as strong predictor of marital adjustment. There were also exposed marked differences in martial adjustment between both family systems. The duration of marriage was also shown to be the significant predictor of marital satisfaction. In accordance with this, there had been demonstrating that long term marriages evident less conflict and had more sources of pleasure like children (Levenson et al., 1993).

Results also highlighted gender differences on emotional intelligence. These results are consistent with prior research as they indicated a reliable difference of couples on emotional intelligence (Bracket et al., 2005). This 
study indicated the no relation in emotional intelligence and no. of children, this finding is concurrent with previous studies as Smith et al. (2008) reflected negligible association between emotional intelligence and family size. While data reflects no significant difference in marital satisfaction, this is not in agreement to some research (Robins et al, 2000) which highlighted more satisfaction in males than females.

Results of this study also suggested that satisfaction and relational communication varies with spousal education. Some past researches showed same results like one significant study indicated that education level is one of the determinant of martial quality (Allendor \& Ghimire, 2013), similarly some researches emphasized that there is no significant relation between level of education and marital satisfaction (Adler, 2010). Findings from current research also reflected the difference in spousal relational relies on the basis of monthly income. This results show their coherence with previous studies, as Zainah et al. (2012) conducted a study that showed significant difference of marital satisfaction with reference to marriage duration and monthly income.

There are some of the limitations of this research. Firstly due to shortage of resources and time constraints etc., the study confined to use short scales for assessment of the variables. Qualitative analysis should also be used in order to ensure more accuracy in assessment of studied variables. Another limitation of this research is that emotional intelligence is one's self character that is link to individual personality development, this factor is complete ignore while studying marital satisfaction of couples. Hence, personality is major factor that influences marital satisfaction. In couple case, not only person itself personality but partner personality also matter a lot in determining their contentment towards each other. So, in future personality will be study as mediating variable in research of marital satisfaction. Thus, conclusion of this research suggested that while assessing the predicting relation among emotional intelligence, relational communication and marital satisfaction. It was conceptualized that one's way of communication enhanced his/her abilities related to emotional intelligence and hence emotional intelligence significantly predict one's satisfaction towards his/her partner.

The emotions play crucial role in one's life and due to the contribution of emotions in determining happy life, especially interpersonal relations, there is dire need for promoting the awareness for enhancing emotional intelligence skills. In Pakistan, there are ever-increasing problem in marriages. This has been realized that emotional intelligence improves the quality of relations between couples and also helps in developing the adaptive skills and adjustment potentials that consequently helps in building strong interpersonal relations. Better emotional intelligence enables one to achieve flexibility, adjustment, satisfaction and contentment in one's life. Since emotional intelligence is of receptive nature, and it carries strong social basis, therefore the individuals learn the ways for strengthening of such emotions that can facilitate communication with others.

The present research revealed that a positive and strong relation exists between the emotional intelligence and marital relations quality; thus this variable could be used in improving human relations and in increasing marital satisfaction between couples. This study has implication for family counseling. Counselors need to consider the relational communication pattern and emotional intelligence in order to improve the couples' satisfaction and interaction towards each other. It is also helpful for counselors to increase the couples' insight regarding each other' emotional intelligence and how that be boasted up.

\section{References}

Alder, E. S. (2010). Age, education level, and length of courtship in relation to marital satisfaction. Masteral thesis, Pacific University.

Allendorf, K., \& Ghimire, D. J. (2013). Determinants of marital quality in an arranged marriage society. Social Science Research, 42(1), 59-70. http://dx.doi.org/10.1016/j.ssresearch.2012.09.002

Amiri, M., Farhoodi, F., Abdolvand, N., \& Bidakhavidi, A. R. (2011). A study of the relationship between big-five personality traits and communication styles with marital satisfaction of married students majoring in public universities of Tehran. Procedia - Social and Behavioral Sciences, 30, 685-689. http://dx.doi.org/10.1016/j.sbspro.2011.10.132 
Relational communication, emotional intelligence, and marital satisfaction

Batool, S. S., \& Khalid, R. (2009). Role of emotional intelligence in marital relationship. Pakistan Journal of Psychological Research, 27(1), 65-88.

Brackett, M. A., Warner, R. M., \& Bosco, J. S. (2005). Emotional intelligence and relationship quality among couples. Personal Relationships, 12, 197-212. http://dx.doi.org/10.1111/j.1350-4126.2005.00111.x

Boyatzis, R. E., \& Sala, F. (2004). The emotional competence inventory (ECI). NY: Nova Science Publishers, Inc.

Burgoon, J. K., \& Hale, J. I. (1987). Validation and measurement of the fundamental themes of relational communication. Communication Monographs, 54, 19-41. http://dx.doi.org/10.1080/03637758709390214

Cordova, J. V., Gee, C. B., \& Warren, L. Z. (2005). Emotional skillfulness in marriage: Intimacy as a mediator of the relationship between emotional skillfulness and marital satisfaction. Journal of Social and Clinical Psychology, 24(2), 218-235. http://dx.doi.org/10.1521/jscp.24.2.218.62270

Dehkordi, A. M. (2012). Relationship between emotional intelligence and marital satisfaction in couples. Journal of Behavioral Sciences, 6(2), 161-169.

Ghorbanshiroudi, S., Khalatbari, J., Salehi, M., Bahari, S., \& Keikhayfarzaneh, M. M. (2011). The relationship between emotional intelligence and life satisfaction and determining their communication skill test effectiveness. Indian Journal of Science \& Technology, 4(11).

Goleman, D. (1998). Working with emotional intelligence. NY: Bantam Books.

Hasani, A. M., Mokhtaree, M., Sayadi, A., Nazer, M., \& Mosavi, S. A. (2012). Study of emotional intelligence and marital satisfaction in academic members of Rafsanjan University of medical sciences. Psychology \& Psychotherapy, 2(2). http://dx.doi.org/10.4172/2161-0487.1000106

Hezardastan, F., et al. (2011). The effect of training through transactional analysis approach on couple's communication patterns. World Applied Sciences Journal, 12(8), 1337-1341.

Konstantin, V. P., Furnham, \& Adrian. (2001). Trait Emotional Intelligence: Psychometric Investigation with Reference to Established Trait Taxonomies. European Journal of Personality, 15, 425-448. http://dx.doi.org/10.1002/per.416

Levenson, R. W., Carstensen, L. L., \& Gottman, J. M. (1993). Long-term marriage: age, gender, and satisfaction long-term marriage: Age, gender, and satisfaction. Psychology and Aging, 8(2), 301-313. http://dx.doi.org/10.1037/0882-7974.8.2.301

Madahi, M. E., Samadzadeh, M., \& Javidi, N. (2013). The communication patterns and satisfaction in married students. Procedia-Social and Behavioral Sciences, 84, 1190-1193. http://dx.doi.org/10.1016/j.sbspro.2013.06.725

Mahnaz, A. D. (2012). Relationship between emotional intelligence and marital satisfaction in couples. Journal of Behavioral Sciences, 6(2), 17-18.

Schutte, N. S., et al. (1998). Development and validation of a measure of emotional intelligence. Personality and Individual Differences, 25, 167-177. http://dx.doi.org/10.1016/S0191-8869(98)00001-4

Peter, S., John, M., \& David, C. (2004). Emotional intelligence: Theory, findings, and implications. U.S.A: Wadsworth.

Raeisipoor, Z., Fallahchai, R., \& Zarei, E. (2013). The study of adult attachment styles, communication patterns and marital satisfaction. Journal of Life Science and Biomedicine, 3(1), 64-68.

Robins, R. W., Caspi, A., \& Moffitt, T. E. (2000). Two personalities, one relationship: Both partners' personality traits shape the quality of their relationship. Journal of Personality and Social Psychology, 79, 251-259. http://dx.doi.org/10.1037/0022-3514.79.2.251

Smith, L., Ciarrochi, J., \& Heaven, P. C. L. (2008). The stability and change of trait emotional intelligence, conflict communication patterns, and relationship satisfaction: A one-year longitudinal study. Personality and Individual Differences, 45, 738-743. http://dx.doi.org/10.1016/j.paid.2008.07.023

Snyder, D. K. (1997). Manual for the Marital Satisfaction Inventory - Revised. Los Angeles, CA: Western Psychological Services.

Zainah, A. Z., Nasir, R., Hashim, R. S., \& Yusof, M. N. (2012). Effects of demographic variables on marital satisfaction. Asian Social Science, 8(9), 46- 49. 
Masood, A., \& Mazahir, S. 